\title{
Study of Bioretention System on Heavy-Metal Removal Effect
}

\author{
Zengchao Liu, ${ }^{1,2}$, Jiake Li ${ }^{1 *}$, Peng Li ${ }^{1}$, Yajiao Li ${ }^{3}$,Wenying Li \\ ${ }^{1}$ State Key Laboratory Base of Eco-Hydraulic Engineering in Arid Area, Xi' an University of Technology, \\ Xi'an 710048, China \\ ${ }^{2}$ School of Materials Science and Chemical Engineering, Xi' an Technological University, \\ Xi' an 710021 , China \\ ${ }^{3}$ School of Architecture and Civil Engineering, Xi' an University of Science and Technology, \\ Xi'an 710054, China
}

Received: 14 April 2017

Accepted: 26 May 2017

\begin{abstract}
Bioretention is a typical low-impact development (LID) technology. This work used four different filler combinations of bioretention tank pilot test devices. Experiments on influence factors and intermittent operation were conducted. A continuous-run experiment was also performed to determine the purification ability of bioretention system on heavy metals. Results showed that the removal efficiency of heavy metals by fly ash tank was the most efficient, with a removal rate reaching $85.57 \%$. The removal effect on highinfluent concentrations in filter was better than that in low-influent concentrations. With increased rainfall time intervals (antecedent dry time), heavy-metal removal efficiency improved. Temperature did not affect the removal efficiency of heavy metals on the whole based on the long duration of intermittent operation experiments. Moreover, the effluent heavy-metal concentration presented a descending trend during each simulation rainfall runoff event. During continuous operation test, heavy metals did not reach the exhaustion point in the experimental tanks, while the effluent concentration increased with increased water volume. According to PLS regression analysis, rainfall time interval was the most important factor affecting $\mathrm{Zn}$ removal rate, followed by filler characteristics, influent volume, and influent concentration.
\end{abstract}

Keywords: bioretention, low-impact development, influence factor, removal efficiency

\section{Introduction}

Urban growth and development negatively affect nearby natural water systems. For example, increases in impervious land areas decrease rainfall infiltration, increase runoff rates and volumes, and decrease runoff travel time. In addition, detrimental water quality changes

*e-mail: xaut_ljk@163.com in stormwater runoff accompany land-use changes that coincide with urbanization [1].

In addition, due to human activities, atmospheric deposition, and other factors, a large number of pollutants accumulate and are discharged into the municipal stormwater sewer by stormwater runoff flushing, then enter the receiving waterbody [2]. Although low concentrations of some heavy metals such as copper $(\mathrm{Cu})$ and zinc $(\mathrm{Zn})$ are essential to plants, humans, and animals, high heavy metal concentrations are toxic [3]. Lead $(\mathrm{Pb})$, on the other 
hand, can have negative effects even at low concentrations [4]. Therefore, heavy metal concentrations in stormwater runoff raise a serious threat, especially for aquatic organisms [5]. Consequently, it is vital to control and reduce heavy metal concentrations in urban stormwater runoff. In order to develop an effective removal strategy of heavy metals in water resources, a number of aspects must be evaluated [6].

Bioretention basins, also called rain gardens, have become a frequent best management practice (BMP) to retain pollutants from road runoff. Stormwater enters a bioretention unit and is purified by physical filtration, adsorption, and ion exchange of soil, microbial transformation and redistribution, evaporation and absorption of plants in the soil and filler layers [7-8]. Laboratory and pilot-scale bioretention box studies have shown that removal efficiencies of $\mathrm{Zn}, \mathrm{Cu}$, and $\mathrm{Pb}$ from a synthetic runoff were typically greater than $95 \%$. The removal rate of total phosphorus and total Kjeldahl nitrogen was approximately $80 \%$ and $50-70 \%$, respectively [9]. Different types of purification effect of heavy metals by bioretention medium, and heavy metals in bioretention medium inside the geometrical shape, accumulation, migration characteristics, and lack of related research, the combination packing is different, and a different blending ratio will affect the removal efficiency of heavy metals by the bioretention system. In this paper, the removal effect of the bioretention retention system on heavy metal, the factors affecting the removal efficiency, and the comparison of intermittent operation and continuous operation are studied to promote better development of bioretention systems.

\section{Materials and Methods}

\section{Device Setup}

Ten bioretention tanks from Nos. 1 to 10 were designed and constructed at an outdoor testing ground of the Key Lab of Northwest Water Resource and Environment Ecology of the Ministry of Education at Xi'an University of Technology in 2013, and each tank had a different structural configuration. Of them, the filler structures of bioretention tanks 7-10 are typical and representative and were therefore selected for the experiments. Bioretention tanks 7, 9, and 10 were used for the experiments of influence factors. Meanwhile, bioretention tanks 7 and 10 were used for the continuous operation experiment. Bioretention tank 8 was used for the intermittent running experiment across different seasons. Experimental bioretention tanks are rectangular in shape $(2 \mathrm{~m}$ long, $0.5 \mathrm{~m}$ wide, and $1.05 \mathrm{~m}$ deep; Fig. 1a). Ligustrum quihoui and Ophiopogon japonicas are planted in the tanks, which
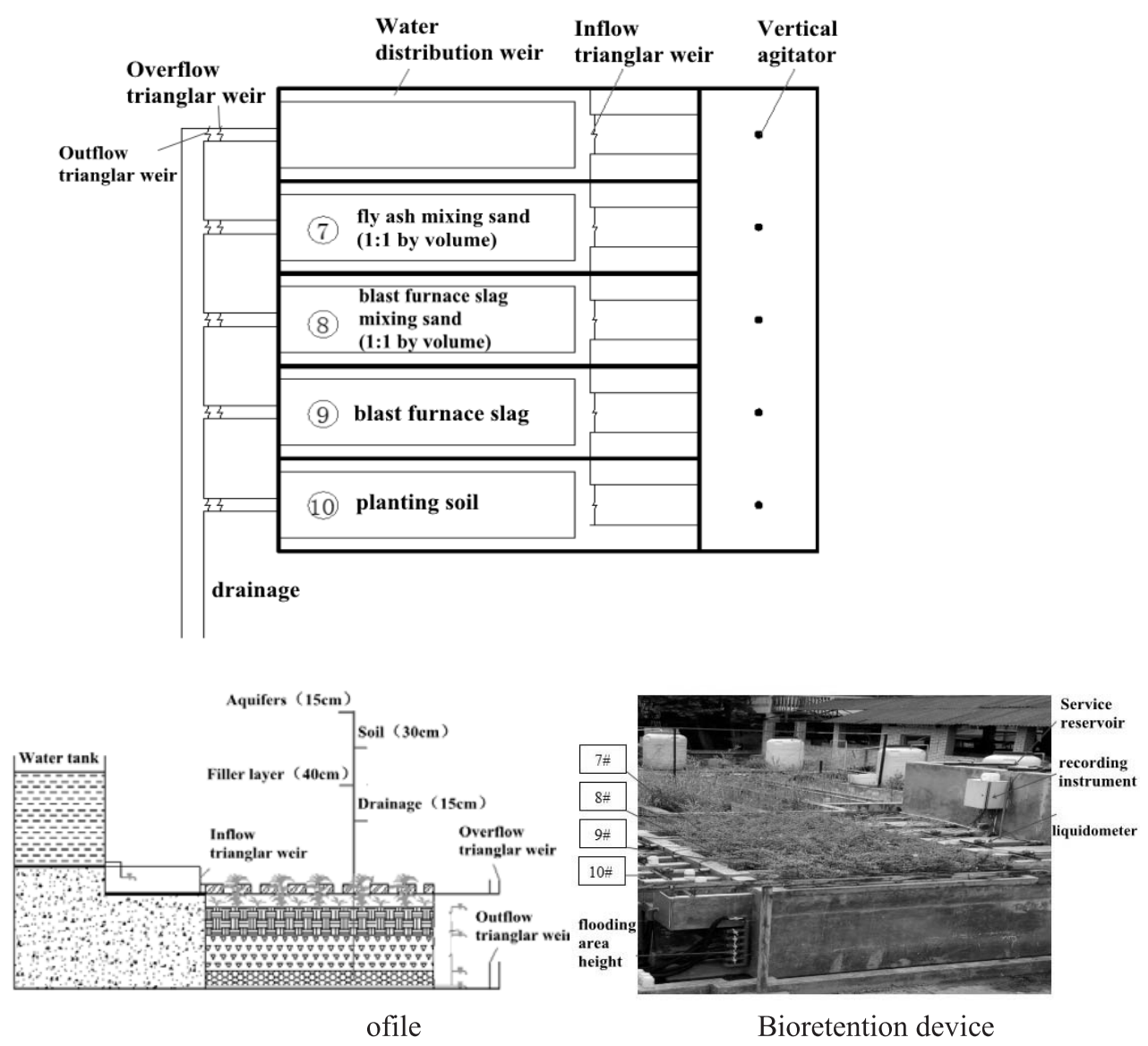

Fig. 1. Bioretention test equipment. 
Table 1. Experimental simulated influent water volumes.

\begin{tabular}{|c|c|c|c|c|c|c|}
\hline$P(\mathrm{a})$ & $t(\min )$ & $q(\mathrm{~L} / \mathrm{s} . \mathrm{ha})$ & $\varphi$ & $F(\mathrm{ha})$ & $V(\mathrm{~L})$ & Level \\
\hline 5 & 120 & 52.0922 & 0.9 & 0.0017 & 573.8472 & High \\
\hline 2 & 120 & 38.7762 & 0.9 & 0.0017 & 427.1591 & Middle \\
\hline 0.5 & 120 & 18.6300 & 0.9 & 0.0017 & 205.2285 & Low \\
\hline
\end{tabular}

Note: $P$-Return period, $t$-Duration of rainfall, $q$-Rainfall intensity, $\varphi$-Runoff coefficient, $F$ - Catchment area, $V$-Influent volume of bioretention tank

are common greening plants. A $30^{\circ}$ triangular weir was installed on the inlet, outlet, and overflow outlet in the bioretention tank (Fig. 1a). There is an XTHJ-recorder before every weir to monitor the flow of water in the inlet, outlet, and overflow. The structural configuration was aquifer layer $(15 \mathrm{~cm})$, planting soil $(30 \mathrm{~cm})$, artificial fillers $(40 \mathrm{~cm})$, and gravel drainage layer $(15 \mathrm{~cm})$ from top to bottom. Artificial fillers in tanks 7-10 consisted of fly ash mixing sand (1:1 by volume), blast furnace slag mixing sand ( $1: 1$ by volume), blast furnace slag, and planting soil, respectively. The bottom of the gravel drainage is layered perforated pipes, and the drain was cupped by permeable geotextile. Between each layer of packing are permeable geotextile and various tanks; besides, the artificial packing layer is not the same as the others and its thickness in each layer is consistent (see photo in Fig. 1c).

\section{Monitoring and Analysis Methodology}

The experiment took copper $(\mathrm{Cu})$, zinc $(\mathrm{Zn})$, and cadmium $(\mathrm{Cd})$ as the main analysis targets. The assumed rainfall intensities of the experiment were calculated through the rainstorm intensity formula of Xi'an city under three return periods of $0.5 \mathrm{a}, 2 \mathrm{a}$, and $5 \mathrm{a}$ [10]. Then the rainfall was obtained with rainfall duration of $2 \mathrm{~h}$. The influent water volumes of the tanks were calculated through the rainfall multiplying catchment area. The results are shown in Table 1 . In this research, influent concentrations remained constant. The concentrations of water distribution were referred to the earlier period monitored results by our research group on urban rainfall runoff pollution [11] (Table 2). This experiment released the water according to the rainfall pattern in Chicago [12], with the rainfall peak coefficient at 0.3 , simulating a complete rainfall process. This Chicago process could meet the general requirements for accuracy, which is widely used at home and abroad.
The $0.45 \mu \mathrm{m}$ filter was used to filtrate the sample; heavy metal concentration was then determined via an AAS Zeenit 700 atom absorption spectroscope. Quantitative analysis for the purification effect of the bioretention system was carried out via Equations 1 and 2.

$$
\begin{gathered}
R_{\mathrm{i}}=\frac{\mathrm{C}_{\mathrm{in}}-\mathrm{C}_{\text {out }}}{\mathrm{C}_{\text {in }}} \times 100 \% \\
R_{\mathrm{c}}=\frac{1}{m} \sum_{i=1}^{m} R_{i}
\end{gathered}
$$

...where $\mathrm{R}_{\mathrm{i}}=$ each of the characteristics of pollutants' $(\mathrm{Cu}, \mathrm{Zn}$, and $\mathrm{Cd})$ removal rates, $\mathrm{R}_{\mathrm{c}}=$ the average removal rate of each pollutant, and $\mathrm{m}=$ total number of samples collected during the event.

\section{Experimental Scheme}

\section{Experiments of Influence Factors}

Bioretention tanks 7, 9, and 10 were moistened using tapwater before each test. Nine tests were conducted to investigate the tank operation effect with different filler combinations, influent concentrations, and rainfall time intervals (antecedent dry time). Through these experiments, the characteristics and laws of bioretention cells on heavy metal pollutant removal were summarized. The specific experimental arrangement is shown in Table 3.

\section{Intermittent Operation Experiments}

The bioretention tank operation effect changes and tendencies were studied under the conditions of Xi'an

Table 2. Experimental simulated influent concentrations.

\begin{tabular}{|c|c|c|c|c|c|c|c|}
\hline Pollutants & $\mathrm{COD}$ & $\mathrm{NO}_{3}-\mathrm{N}$ & $\mathrm{NH}_{3}-\mathrm{N}$ & $\mathrm{TP}$ & $\mathrm{Cu}$ & $\mathrm{Zn}$ & $\mathrm{Cd}$ \\
\hline $\begin{array}{c}\text { High concentration } \\
(\mathrm{mg} / \mathrm{L})\end{array}$ & 600 & 14 & 6 & 2.5 & 0.1 & 1.5 & 0.05 \\
\hline $\begin{array}{c}\text { Medium concentration } \\
(\mathrm{mg} / \mathrm{L})\end{array}$ & 300 & 8 & 3 & 1.0 & 0.05 & 0.8 & 0.03 \\
\hline Reagent & $\mathrm{C}_{6} \mathrm{H}_{12} \mathrm{O}_{6}$ & $\mathrm{KNO}_{3}$ & $\mathrm{NH}_{4} \mathrm{Cl}$ & $\mathrm{KH}_{2} \mathrm{PO}_{4}$ & $\mathrm{CuCl}_{2}$ & $\mathrm{ZnSO}_{4}$ & $\mathrm{CdCl}_{2}$ \\
\hline
\end{tabular}


Table 3. Design of influence factor experiments.

\begin{tabular}{|c|c|c|c|c|c|}
\hline $\begin{array}{c}\text { Number of water } \\
\text { quality test }\end{array}$ & $\begin{array}{c}\text { Concentration of } \\
\text { pollutants }\end{array}$ & $\begin{array}{l}\text { The height of submerged zone } \\
\qquad /(\mathrm{mm})\end{array}$ & $\begin{array}{l}\text { Intervals } \\
\qquad /(\mathrm{d})\end{array}$ & $\begin{array}{l}\text { Experimental } \\
\text { date }\end{array}$ & $\begin{array}{l}\text { Water quantity } \\
\qquad /(\mathrm{L})\end{array}$ \\
\hline clean water experiment & - & - & - & - & - \\
\hline \multirow[t]{2}{*}{ Test 1} & medium & 0 & & $2015-5-20$ & 573.8472 \\
\hline & & & 7 & & \\
\hline \multirow[t]{2}{*}{ Test 2} & medium & 150 & & $2015-5-27$ & 573.8472 \\
\hline & & & 7 & & \\
\hline \multirow[t]{2}{*}{ Test 3} & medium & 0 & & $2015-6-03$ & 573.8472 \\
\hline & & & 15 & & \\
\hline \multirow[t]{2}{*}{ Test 4} & medium & 0 & & $2015-6-18$ & 573.8472 \\
\hline & & & 7 & & \\
\hline \multirow[t]{2}{*}{ Test 5} & medium & 0 & & $2015-6-25$ & 573.8472 \\
\hline & & & 3 & & \\
\hline \multirow[t]{2}{*}{ Test 6} & medium & 0 & & $2015-6-28$ & 573.8472 \\
\hline & & & 7 & & \\
\hline \multirow[t]{2}{*}{ Test 7} & medium & 0 & & $2015-7-05$ & 427.1591 \\
\hline & & & 7 & & \\
\hline \multirow[t]{2}{*}{ Test 8} & medium & 0 & & $2015-7-12$ & 573.8472 \\
\hline & & & 7 & & \\
\hline Test 9 & high & 0 & & 2015-7-19 & 573.8472 \\
\hline
\end{tabular}

climate (plant transpiration, evapotranspiration, and soil restores). Bioretention tank 8 was selected to perform the intermittent operational experiment with medium influent concentration at the 5a return period rainfall. Intermittent operation started from May 2015 to December 2015, and the simulated rainwater experiment was conducted on tank 8 (artificial filler layer is a mixture of blast furnace slag and sand with the ratio 1:1) every 30 days and lasted for eight months. There were eight water quality tests.

\section{Continuous Operational Experiments}

During the period of rainfall, filters mainly depend on adsorption and precipitation via the padding to remove the runoff pollutant. To study the exhaustion performance of filler, a penetration curve graph was used. That is, under continuous inflow, the padding adsorption exhaustion point was determined through comparing the influent concentration and effluent concentration. Tanks 7 and 10 were selected to do the experiments, and influent concentration was kept at medium. Considering that continuous dewatering may make padding lose its adsorption capacity after several hours, the influent load transitioned gradually from small to heavy. Two tanks were all running for $24 \mathrm{~h}$ with a 0.5 -year return period influent volume, $12 \mathrm{~h}$ with a two-year return period influent volume, and $8 \mathrm{~h}$ with a five-year return period influent volume. The influent concentration was constant, and the valve opening also remained constant. The influent samples were taken every $2 \mathrm{~h}$, and the effluent samples were taken every $0.5 \mathrm{~h}$ when the water started to flow out; water sample concentrations in different times were then determined. If the $\mathrm{C} /\left[\mathrm{C}_{0}(1-10 \%)\right] \geq 1$ for three consecutive hours, the capacity of packing was depleted.

\section{Results and Discussion}

\section{Influence Factor Result Analysis}

The primary factors influencing the removal effects of bioretention tank on heavy metal include padding combination, pollutant concentration, rainfall time interval, and so on. Tanks 7, 9, and 10 were selected to determine the important order of these influencing factors. The evaluation index is the pollutant concentration removal rate.

\section{Filler Combinations}

The simulation dry time of tests 3,5 , and 8 before the rainfall is $7 \mathrm{~d}$; the influent concentration is medium concentration and five-year return period of rainwater. The test results are shown in Fig. 2.

Fig. 2 shows that the removal effect of $\mathrm{Cu}$ is better than those of other heavy metals, and partial effluent 
a)

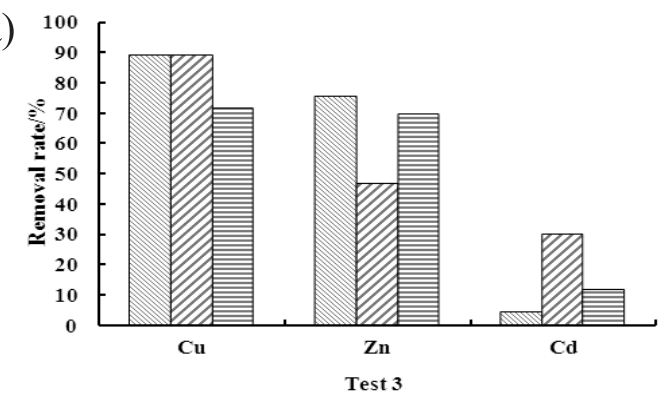

b)

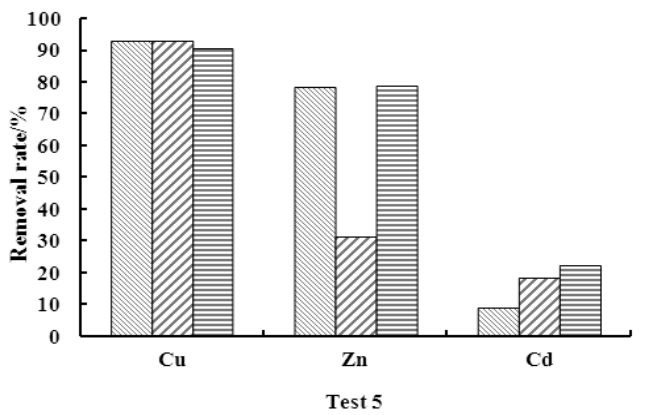

c)

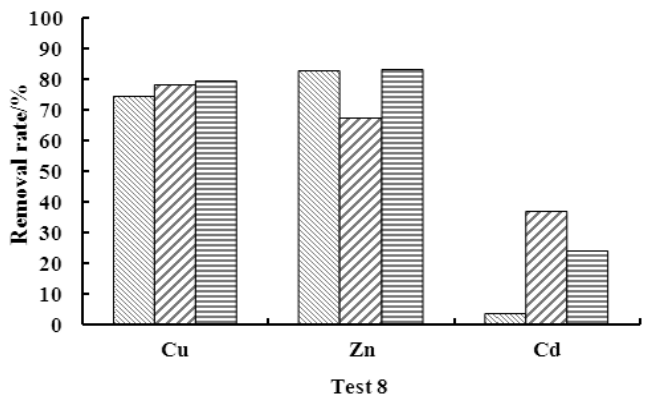

Fig. 2. Influence of filler combination of removal efficiency.

concentrations were lower than the detection limit of an atomic absorption spectrophotometer (AAS Zeenit700). The removal effects of $\mathrm{Cu}$ in three tanks $(7,9$, and 10) were similar. Of them, tank 7 (packed with fly ash mixing sand) is the most efficient, with an average elimination rate of $85.57 \%$. The removal effect of $\mathrm{Zn}$ in tanks 7 and 10 (packing with planting soil) were similar, with the average elimination rates of $78.83 \%$ and $77.17 \%$, respectively. $\mathrm{Zn}$ removal effect in tank 9 (packed with blast furnace slag) is relatively poor, with an average removal rate of $48.4 \%$. Heavy metals were always purified through the interception of surface materials, internal physical adsorption, and absorption of plants in bioretention, and most of the particulate heavy metals in rainwater were adsorbed on suspended solids, then removed through filtration [13]. In urban rainwater runoff, $\mathrm{Cu}, \mathrm{Zn}, \mathrm{Pb}$, and Cd particulates respectively account for $67 \%, 52 \%, 97 \%$, and $83 \%$ of the total [14]. However, the dissolved $\mathrm{Zn}$ contributes most of the total. A number of studies have indicated that the metal competitive sorption would be in the order of $\mathrm{Pb}>\mathrm{Cu}>\mathrm{Zn}$ [15]. But elimination effects of $\mathrm{Cd}$ in these three tanks were not very efficient, which may be due to too low influent $\mathrm{Cd}$ concentration and close to the detection limit of atomic absorption spectrophotometer. Compared with other tanks, tank 9 (packed with blastfurnace slag) was good at the removal of Cd. Overall, the
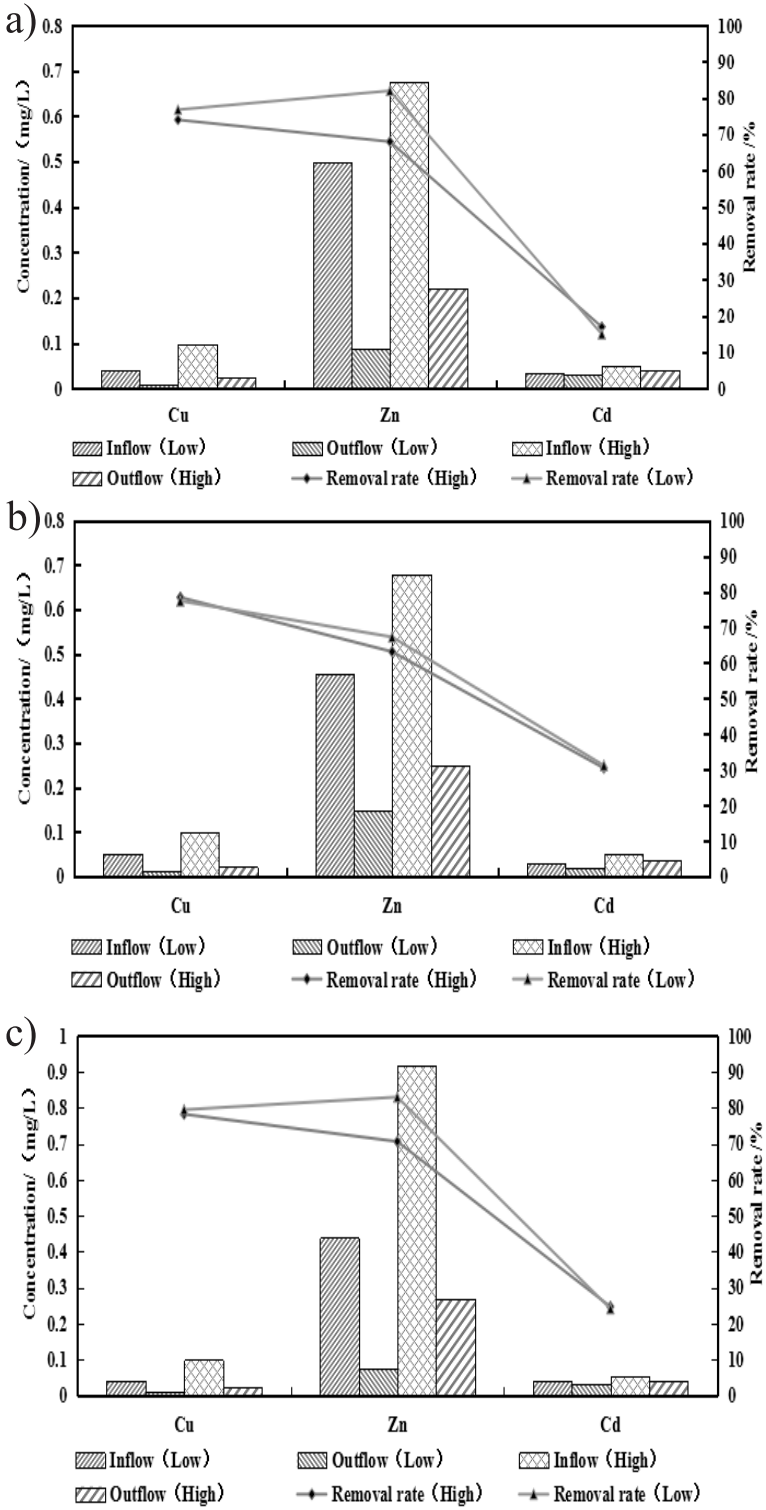

Fig. 3. Effects of removal efficiency on heavy metals with different bioretention media: a) Tank 7, b) Tank 9, c) Tank 10.

removal rates of heavy metal at bioretention tanks 7 and 10 were great.

\section{The Rainfall Runoff Concentration of Heavy Metals}

With two inflow concentrations of medium and high (Table 3), the removal effects of different media on two heavy metals concentrations were obtained from tests 8 and 9, which were shown in Fig. 3.

The effluent concentration of each heavy metal increased with the increase of influent concentration, while the removal rates of $\mathrm{Cu}$ and $\mathrm{Cd}$ at high influent concentration did not differ significantly with those at low influent concentration. For tanks 7, 9, and 10, the removal rate of $\mathrm{Cu}$ was above $75 \%$, and that of $\mathrm{Cd}$ was about $20 \%$. 
Although the removal rate of $\mathrm{Zn}$ was affected by influent concentration in tanks 7 and 10, it was not affected by influent concentration in tank 9. The removal rate of $\mathrm{Zn}$ under low influent concentration was higher than that under high influent concentration, and the minimum removal rate of $\mathrm{Zn}$ was $63 \%$. On the whole, the influent concentration of heavy metals had little effect on the removal efficiency of the bioretention system.

\section{Rainfall Time Interval}

Tests 4-6 were used to study the influence of rainfall time interval on the removal effect. The experimental conditions of the three tests are: medium influent concentration, five-year return period inflow water volume, and rainfall time intervals of $15 \mathrm{~d}, 7 \mathrm{~d}$, and $3 \mathrm{~d}$. The experimental results are shown in Fig 4.

The changes of removal rate with rainfall time interval for $\mathrm{Cu}, \mathrm{Zn}$, and $\mathrm{Cd}$ in tanks 7, 9, and 10 are shown in Fig. 4. The removal rate changes of $\mathrm{Cu}$ and $\mathrm{Zn}$ are obvious
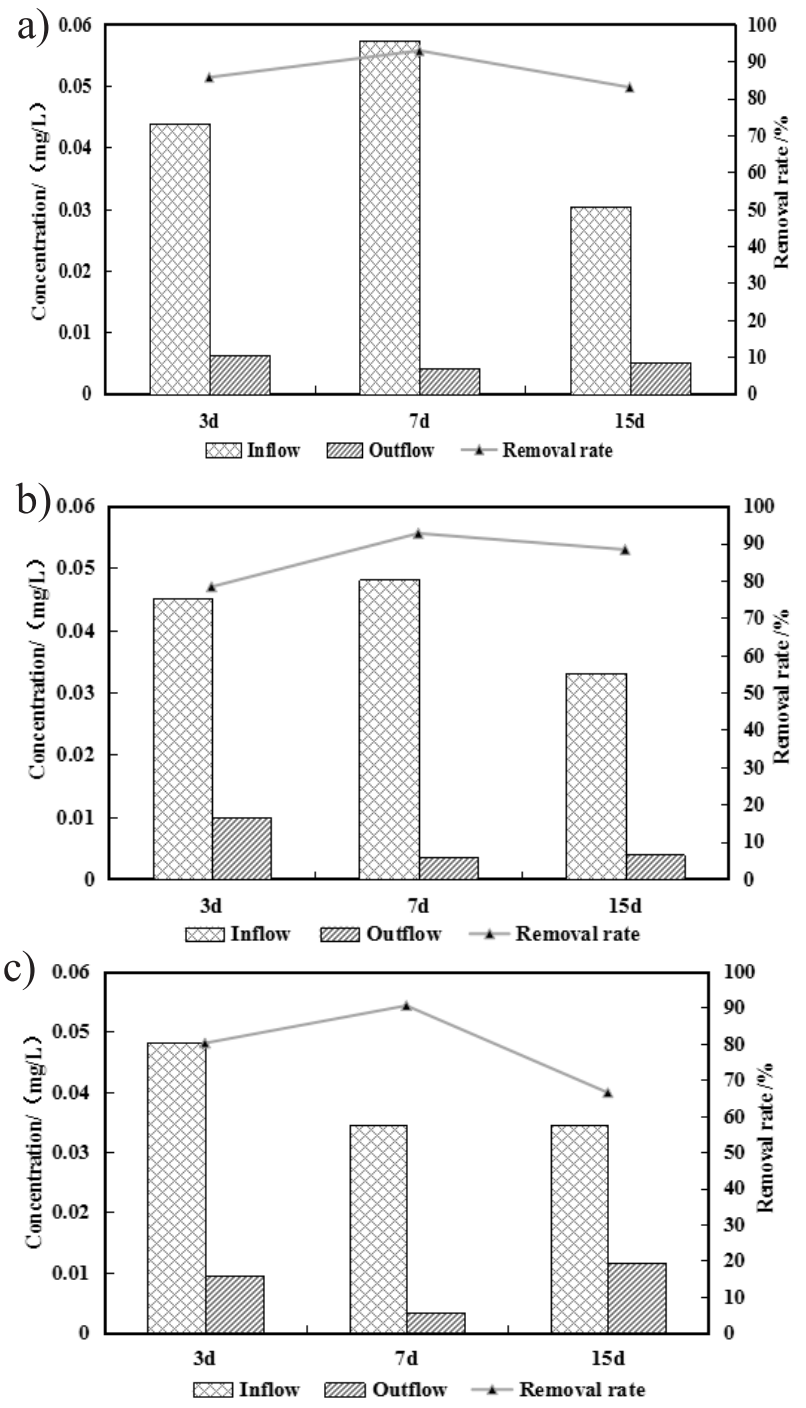

Fig. 4. Effects of rainfall interval on heavy metals with different bioretention media: a) Tank 7, b) Tank 9, c) Tank 10. with test time interval in the three tanks. With the increase of rainfall time interval, the removal rate of $\mathrm{Cu}$ in the three tanks first increased and then decreased. The removal efficiency of $\mathrm{Cu}$ was best when the interval of rainfall was seven days and the average removal rate was above $90 \%$. The removal rate of $\mathrm{Zn}$ in the three tanks increased with the increase of rainfall interval. The highest removal rate was observed when the rainfall interval was 15 days, and the highest removal rate of tank 7 was $87 \%$. The $\mathrm{Cd}$ removal rates in the three tanks had no obvious changes with time interval, and the time interval had little influence on the removal of $\mathrm{Cd}$. In general, the rainfall time interval has a great impact on heavy-metal removal efficiency. The longer the time interval, the higher the heavy metal removal rate. Dryness may affect soil structure (e.g., porosity increase and cracking occurrence) and plant activity, including removal efficiency of heavy metals [16]. Although the literature [17] showed that short-term dryness had no effect on heavy metal removal, effluent heavy metal concentration increases after three weeks; in the case of a submerged area and carbon source, however, even if the dry period had been extended, $\mathrm{Cu}$ and $\mathrm{Pb}$ still maintained the best removal rates.

\section{Testing the Effect of Intermittent Operation}

We conducted eight water quality tests. The experimental conditions were medium inflow concentration, and $2 \mathrm{~h}$ rainfall runoff inflow water volume with five-year return period. For each test, inflow water volume, influent heavy metal concentration, and the antecedent dry time were kept consistent. The influences of weather conditions and padding properties on the purification effect of tanks were compared.

\section{Concentration Removal Rate}

Fig. 5 shows the pollutant removal effect having no certain tendency. The entire experiment underwent high and low temperature seasons. The eight-month-long water quality purification effects demonstrated that the removal rates were $70.3-86 \%$ for $\mathrm{Cu}, 37.5-79.4 \%$ for $\mathrm{Zn}$, and 20.2-39.5\% for Cd. Accordingly, temperature had little influence on the retention tank purifying heavy metal.

\section{Concentration Process Line}

For different heavy metals, a bioretention system has different removal effects, and effluent concentrations present different rules. The concentration process line is shown in Figure 6. The influent concentration during each test was constant. Effluent samples were collected once every 15 minutes after outflow was discharged, then the sample concentrations were examined.

Heavy metals of urban stormwater runoff are removed by intercepting surface media, physisorption of internal media, and absorption of plants in the bioretention system [18]. Laboratory studies on heavy metal removal rates 


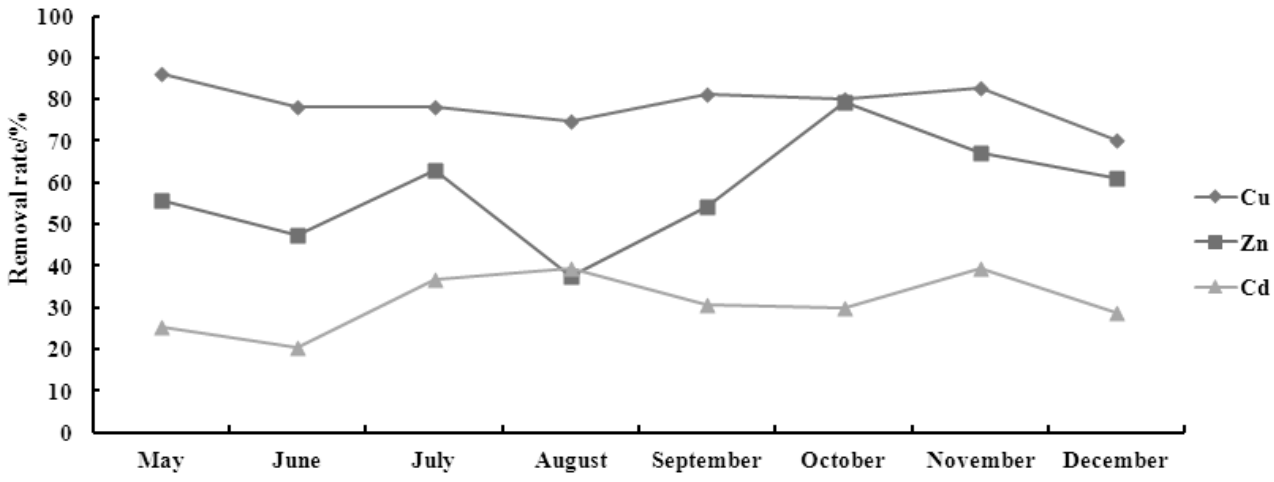

Fig. 5. Removal effects of pollutant concentrations.

in stormwater show that most of the heavy metals were removed on the surface of media; even the removal rate of the filter layer without plants is higher than that with plants [6]. Therefore, the removal of heavy metals of stormwater runoff by bioretention media had definite selectivity. In addition, plants and their roots have important effects on dissolution and migration of heavy metals in the soil. As shown in Fig. 6, in the eight water quality tests using tank 8, the effluent concentrations of $\mathrm{Cu}$ and $\mathrm{Zn}$ showed a decreasing trend. Due to low influent Cd concentration, effluent $\mathrm{Cd}$ concentration was unstable. However, it was decreased on the whole. In general, the bioretention tank has good removal efficiency for heavy metals.

\section{Continuous Operation Test}

The artificial packing layer of tank 7 is fly ash with sand, and it has good water quality purification effect in
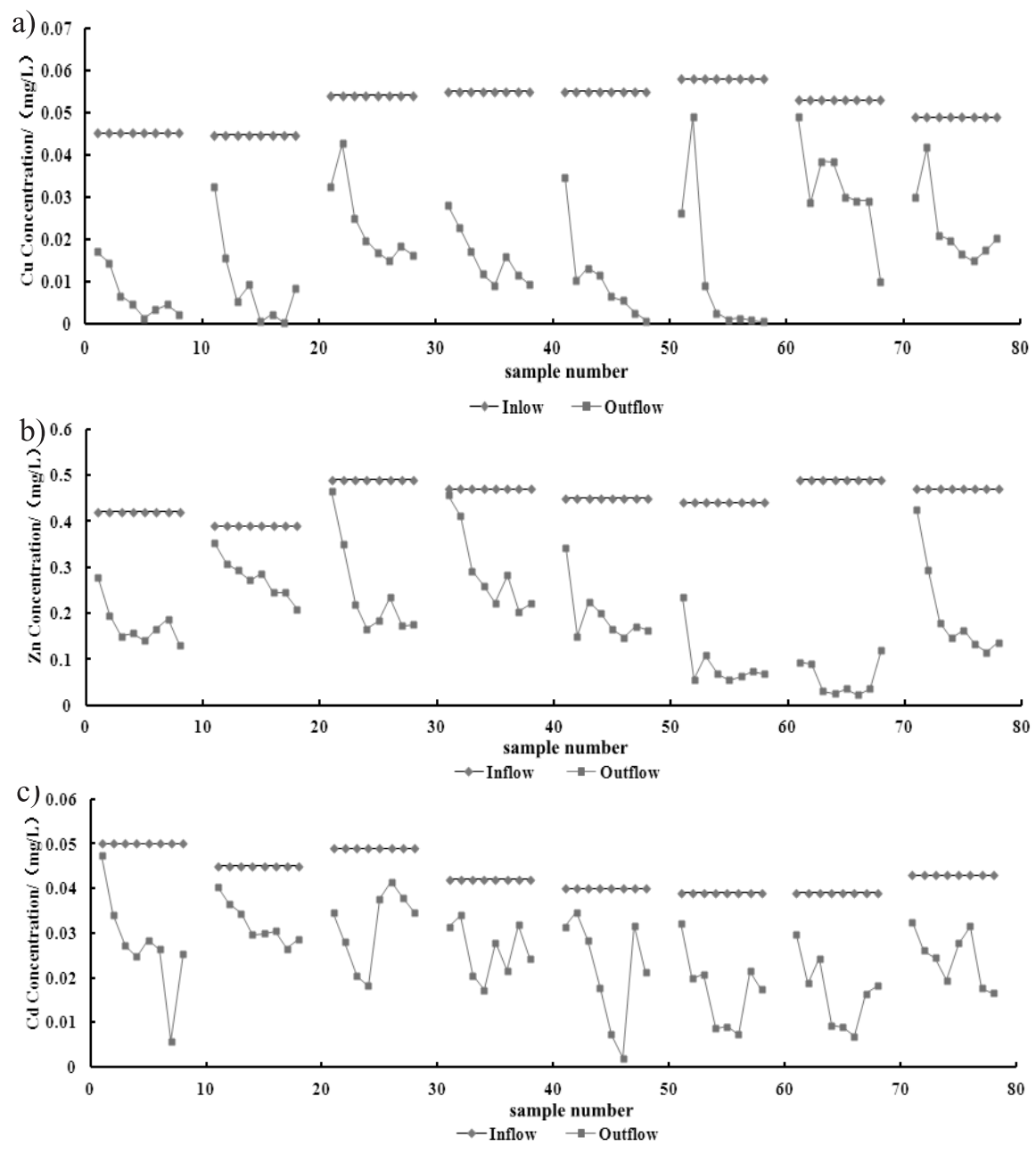

Fig. 6. Concentration process line of outflow pollutants. 

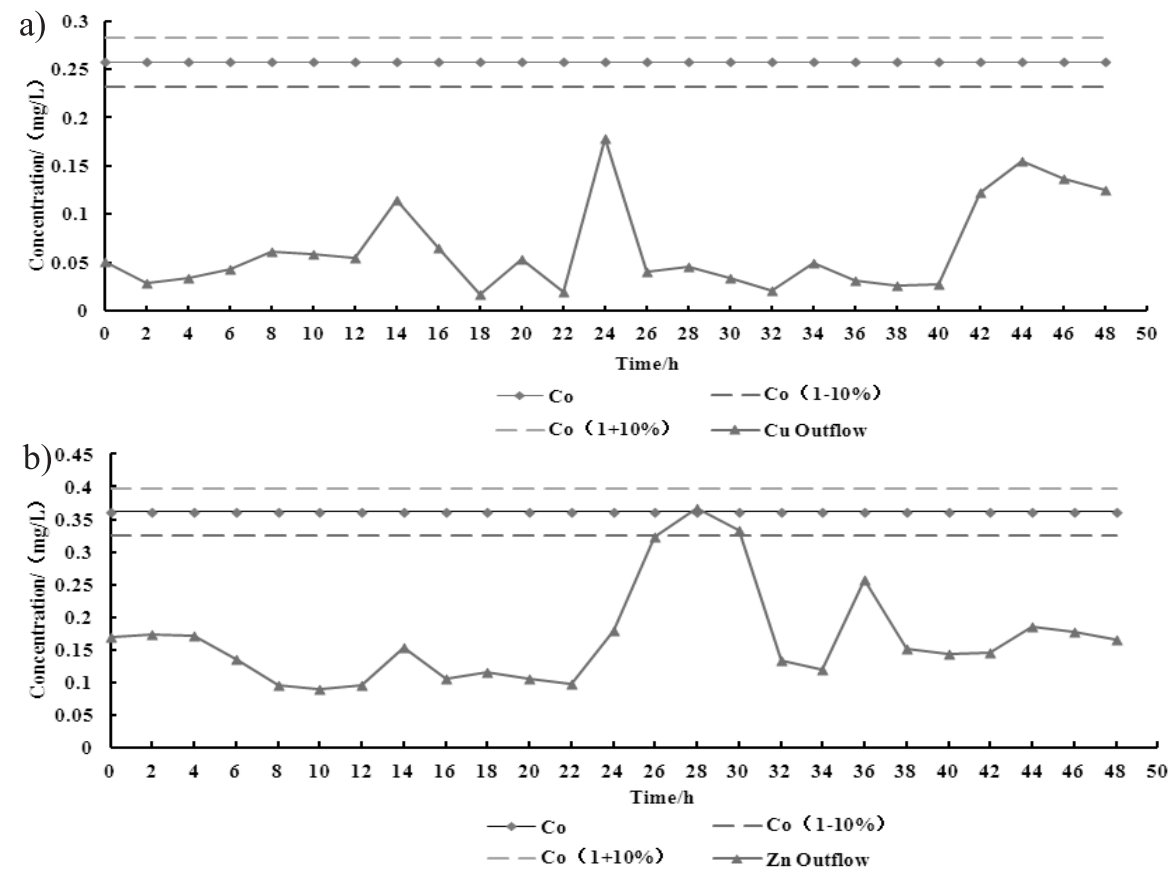

Fig. 7. Exhausted experiment result of No. 7 bioretention tank.

the previous tests mentioned above. Therefore, tank 7 was selected to conduct a continuous operation test to observe the purification ability of bioretention, and the results are shown in Fig. 7.

In Fig. 7a), $\mathrm{Cu}$ did not reach the exhaustion point of media in tank 7 during the whole test process. The effluent concentration of $\mathrm{Cu}$ increased with increasing influent volume, which may be due to $\mathrm{Cu}$ absorbed on the surface of the filler particles or soil being washed down by strong water flow. In Fig. 7b), under small hydraulic load, effluent concentrations of $\mathrm{Zn}$ are stable and low. The phenomenon of $\mathrm{C}>\left[\mathrm{C}_{0}(1-10 \%)\right]$ for $\mathrm{Zn}$ appeared after $26 \mathrm{~h}$. Under medium hydraulic load, the effluent concentrations of $\mathrm{Zn}$ are relatively high. While under large hydraulic load, $\mathrm{Zn}$ returns to a low effluent concentration.

The artificial packing layer for tank 10 is planting soil, which has good removal for heavy metal, as shown in Fig. 8. Under low hydraulic load, discharge concentrations of $\mathrm{Cu}$ are low. With the increase of hydraulic
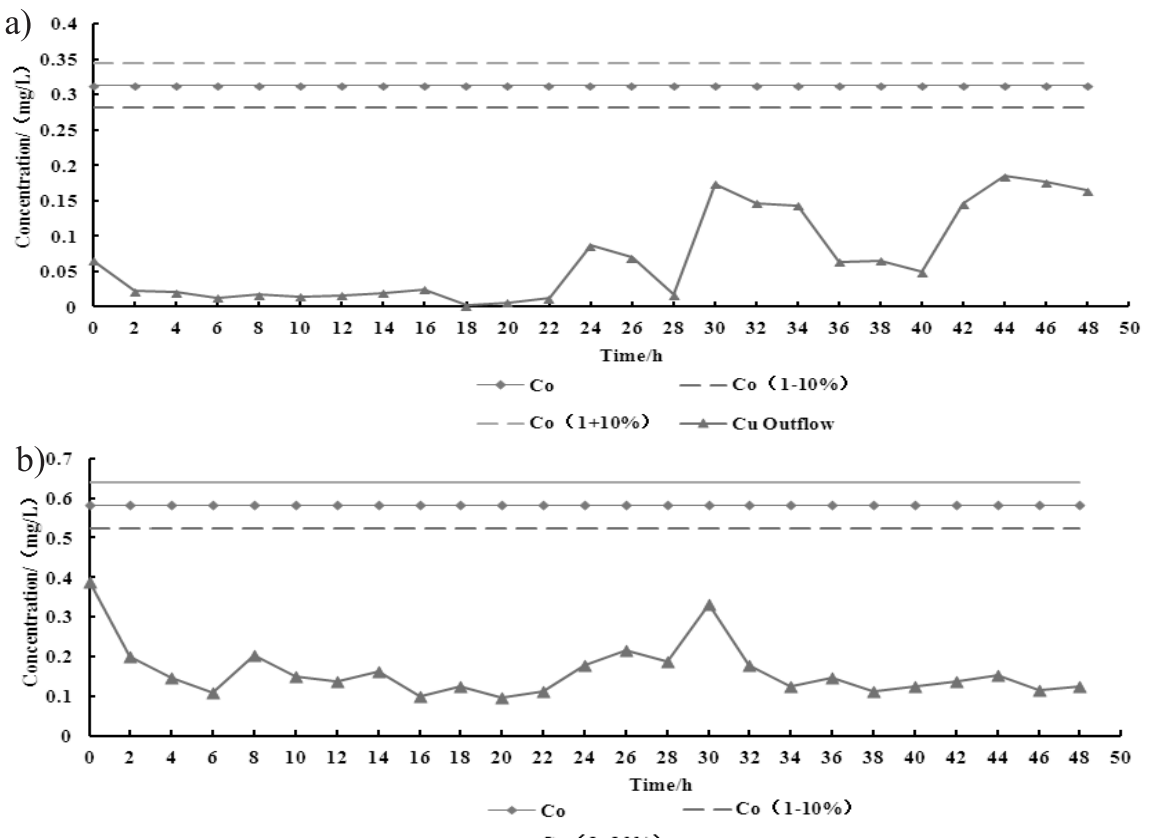

Fig. 8. Exhausted experiment result of No. 10 bioretention tank. 
Table 4. Modeling samples of $\mathrm{Zn}$ concentration removal rate and its impact factors.

\begin{tabular}{|c|c|c|c|c|c|c|}
\hline Test number & $\begin{array}{l}\text { Device } \\
\text { number }\end{array}$ & $\begin{array}{l}\text { Influent Zn concentration } \\
\qquad /(\mathrm{mg} / \mathrm{L})\end{array}$ & $\begin{array}{l}\text { Influent water volume } \\
\qquad /(\mathrm{L})\end{array}$ & $\begin{array}{l}\text { Rainfall time } \\
\text { interval /(d) }\end{array}$ & $\begin{array}{l}\text { Filler factor } \\
/\left(10^{-3} \mathrm{~d} / \mathrm{m}\right)\end{array}$ & $\begin{array}{c}\text { Zn removal rate } \\
\qquad /(\%)\end{array}$ \\
\hline \multirow{3}{*}{ Test 1} & 7 & 0.37 & 529.73 & 7 & 552.241 & 79.7 \\
\hline & 9 & 0.37 & 532.14 & 7 & 150.218 & 60.4 \\
\hline & 10 & 0.37 & 520.69 & 7 & 135.264 & 69.3 \\
\hline \multirow{3}{*}{ Test 2} & 7 & 0.61 & 536.49 & 7 & 552.241 & 62.4 \\
\hline & 9 & 0.61 & 535.11 & 7 & 150.218 & 59.6 \\
\hline & 10 & 0.61 & 532.53 & 7 & 135.264 & 70.3 \\
\hline \multirow{3}{*}{ Test 4} & 7 & 0.53 & 525.88 & 15 & 552.241 & 87 \\
\hline & 9 & 0.53 & 539.16 & 15 & 150.218 & 80.1 \\
\hline & 10 & 0.53 & 525.43 & 15 & 135.264 & 80.9 \\
\hline \multirow{3}{*}{ Test 5} & 7 & 0.51 & 532.82 & 7 & 552.241 & 78.1 \\
\hline & 9 & 0.51 & 525.21 & 7 & 150.218 & 73.2 \\
\hline & 10 & 0.51 & 515.11 & 7 & 135.264 & 78.8 \\
\hline \multirow{3}{*}{ Test 6} & 7 & 0.48 & 546.71 & 3 & 552.241 & 53.6 \\
\hline & 9 & 0.48 & 533.03 & 3 & 150.218 & 50.4 \\
\hline & 10 & 0.48 & 524.76 & 3 & 135.264 & 60.3 \\
\hline \multirow{3}{*}{ Test 7} & 7 & 0.48 & 353.76 & 7 & 552.241 & 82.3 \\
\hline & 9 & 0.48 & 361.49 & 7 & 150.218 & 73.6 \\
\hline & 10 & 0.48 & 359.63 & 7 & 135.264 & 77.4 \\
\hline \multirow{3}{*}{ Test 9} & 7 & 1.1 & 518.86 & 7 & 552.241 & 83.6 \\
\hline & 9 & 1.1 & 517.71 & 7 & 150.218 & 73.7 \\
\hline & 10 & 1.1 & 503.54 & 7 & 135.264 & 70.6 \\
\hline
\end{tabular}

load, discharge concentrations of $\mathrm{Cu}$ also show an increasing trend. The discharge concentration of $\mathrm{Zn}$ is relatively stable. The purification of bioretention on heavy metals mainly depends on surface layer medium interception and internal medium physical-adsorption; most of the particulate heavy metals are adsorbed on the suspended solids and will be removed through filtering in the surface [13]. Concentrations of particle states of $\mathrm{Cu}, \mathrm{Zn}, \mathrm{Pb}$, and $\mathrm{Cd}$ accounted for $67 \%, 52 \%, 97 \%$, and $83 \%$, and $\mathrm{Zn}$ has the highest dissolved state proportion [14]. Because the dissolved metals are easily absorbed, with the increase of the influent load, $\mathrm{Cu}$ absorbed on soil particle surface will be washed off to increase effluent concentration.

\section{Modeling and Analysis of Zn Removal Effect Based on PLS Method}

In the statistical analysis of efficiency of $\mathrm{Zn}$ removal, only one dependent variable $\mathrm{Y}$ ( $\mathrm{Zn}$ removal rate) was set with the independent variable $X$, including water pollutant concentrations, water hydraulic load, rainfall time interval, and filler factor. The drying time and packing factor were found to have a strong linear relationship with the removal rate of pollutants via curve analysis.

$$
\hat{y}=b_{0}+b_{1} x_{1}+b_{2} x_{2}+b_{3} x_{3}+b_{4} x_{4}
$$

... where $\mathrm{y}=\mathrm{Zn}$ removal rate $(\%), \mathrm{x}_{1}=$ influent concentration $(\mathrm{mg} / \mathrm{L}), \mathrm{x}_{2}=$ water hydraulic load $(\mathrm{L})$, $\mathrm{x}_{3}=$ rainfall time interval $(\mathrm{d})$, and $\mathrm{x}_{4}=$ filler factor (filler adsorption amount divided by the infiltration rate) $\left(10^{-3} \mathrm{~d} / \mathrm{m}\right)$.

The Nash-Sutcliffe coefficient of efficiency $E$ is one of the indices most frequently used to assess the accuracy of hydrologic models [19]. It is calculated according to:

$$
E=1-\frac{\sum_{\mathrm{i}=1}^{N}\left(X_{\mathrm{i}}-Y_{\mathrm{i}}\right)^{2}}{\sum_{\mathrm{i}=1}^{N}\left(Y_{\mathrm{i}}-\bar{Y}\right)^{2}}
$$

...where $\mathrm{X}_{\mathrm{i}}$ is the predicted (simulated) value, $\mathrm{Y}_{\mathrm{i}}$ is the monitored value, and $\bar{Y}$ is the average of all monitored values. $\mathrm{E}=1$ indicates complete agreement between the measured and calculated values. A negative value of E means that the forecast is not satisfactory. Pearson 
Table 5. Test samples of measured and predicted $\mathrm{Zn}$ removal rates and impact factors.

\begin{tabular}{|c|c|c|c|c|c|c|c|}
\hline $\begin{array}{c}\text { Test } \\
\text { number }\end{array}$ & $\begin{array}{c}\text { Device } \\
\text { number }\end{array}$ & $\begin{array}{c}\text { Influent Zn } \\
\text { concentration } \\
/(\mathrm{mg} / \mathrm{L})\end{array}$ & $\begin{array}{c}\text { Influent water } \\
\text { volume } \\
/(\mathrm{L})\end{array}$ & $\begin{array}{c}\text { Rainfall time } \\
\text { interval } /(\mathrm{d})\end{array}$ & $\begin{array}{c}\text { Filler factor } \\
/\left(10^{-3} \mathrm{~d} / \mathrm{m}\right)\end{array}$ & $\begin{array}{c}\text { Zn removal } \\
\text { rate } \\
/(\%)\end{array}$ & $\begin{array}{c}\text { Zn predicted } \\
\text { values } \\
/ \%\end{array}$ \\
\hline \multirow{3}{*}{ Test 3 } & 7 & 0.58 & 526.03 & 7 & 552.241 & 79.7 & 69.98 \\
\cline { 2 - 9 } & 9 & 0.58 & 531.52 & 7 & 150.218 & 60.4 & 58.68 \\
\hline \multirow{3}{*}{ Test 8 } & 10 & 0.58 & 520.81 & 7 & 135.264 & 69.3 & 73.58 \\
\cline { 2 - 9 } & 7 & 0.51 & 507.05 & 7 & 552.241 & 62.4 & 73.26 \\
\cline { 2 - 8 } & 10 & 0.51 & 525.44 & 7 & 150.218 & 51.3 & 53.69 \\
\hline
\end{tabular}

correlation coefficient $\mathrm{R}^{2}$ measures the linear dependence of measured and calculated values.

Twenty-one groups of data from seven rainfall events were considered as modeling samples. The modeling samples are listed in Tables 4 and 5, and Tests 3 and 8 were used in the model verification. The calibrated original variable model is shown as Eq. (5).

$$
\hat{y}=6.9594+0.1776 x_{1}-0.3403 x_{2}+0.7939 x_{3}+0.2503 x_{4}
$$

The simulation results are shown in Fig. 9a). The $\mathrm{E}$ values of calibration and validation are, respectively, 0.646 and 0.768 . The correlation coefficient $\mathrm{R}^{2}$ between all simulated values and measured values is 0.654 . These show that the simulated values fit well with measured values.
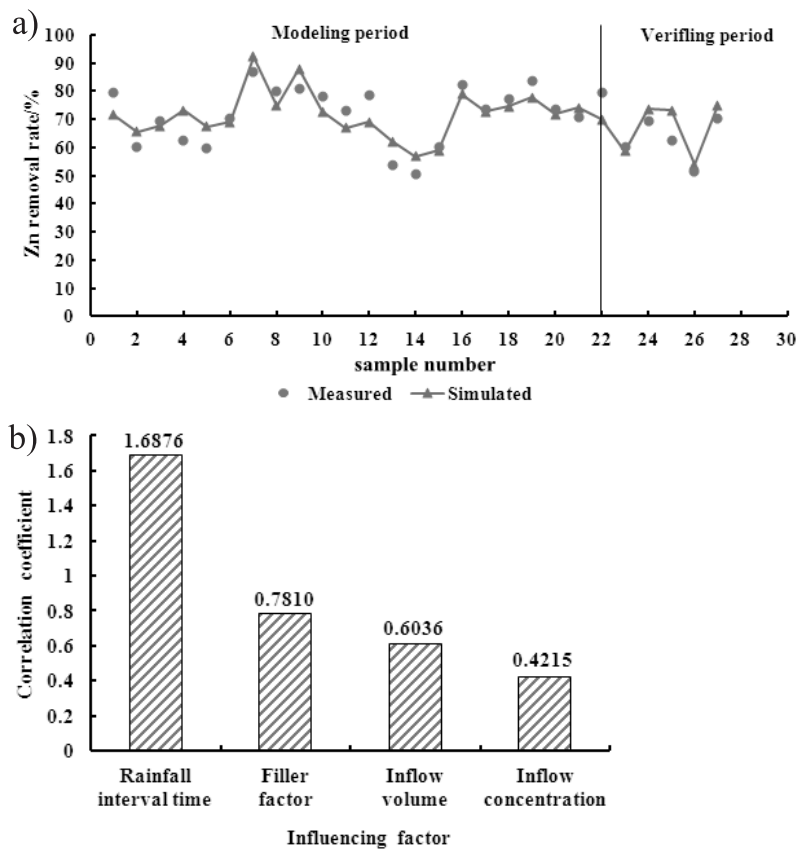

Fig. 9. Modeling of Zn removal effect based on PLS method: a) Comparison of simulated and measured values, b) Importance analysis of influencing factors.
Among the four relatively important factors, rainfall time interval, influent concentration, and influent volume are the external influence factors for bioretention, whereas filler factor size is an internal factor. Through correlation calculation (Fig. 9b), rainfall time interval with the correlation coefficient value of 1.6876 is concluded to be the most important factor influencing $\mathrm{Zn}$ removal effect; the other important factors are filler characteristic, influent volume, and influent concentration in turn.

\section{Conclusions}

As a typical rainwater runoff control measure, bioretention combines the LID technology with rainwater reuse technologies and optimizes the best management practices with the highest use value. Through influence factor experiments, intermittent operation experiments, and continuous operation experiments, as far as the heavy metal removal effects are concerned, fly ash was better than planting soil, and blast furnace slag was the worst; heavy metal removal effect on high influent concentrations was better than on low influent concentrations; the removal efficiency of heavy metals increased with rainfall time interval; and temperature did not affect the removal efficiency of heavy metals on the whole, and effluent heavy metal concentration decreased with time during each test. Rainfall time interval was the most important factor influencing Zn removal effect; the other important factors are filler, influent volume, and influent concentration - in that order.

In future research, the influences of such factors as plant root density, and microbial species and quantity on bioretention purification effects can be explored; the number of influence factor levels should be increased to obtain a better grasp on the characteristics of running parameters about the system; the pollutant migration conversion process in bioretention system should be analyzed and understood; and the purification mechanism model for the bioretention system can be established. 


\section{Acknowledgements}

This research was financially supported by the Natural Science Foundation of Shaanxi Province (No. 2015JZ013) and the National Natural Science Foundation of China (Nos. 51279158 and 51409211).

\section{References}

1. BREZONIK P.L., STADELMANN T.H. Analysis and predictive models of stormwater runoff: volumes, loads, and pollutant concentrations from watersheds in the Twin cities metropolitan area, Minnesota, USA. Water Res. 36 (7), 1743, 2002.

2. MOHAMMED A., BABATUNDE A. O. Modelling heavy metals transformation in vertical flow constructed wetlands. Ecol. Model. 354, 62, 2017.

3. NADELLA S.R., FITZPATRICK J.L., FRANKLIN N., BUCKING C., SMITH S., WOOD C.M. Toxicity of dissolved $\mathrm{Cu}, \mathrm{Zn}$, Niand $\mathrm{Cd}$ to developing embryos of the blue mussel (Mytilustrossolus) and the protective effect of dissolved organic carbon. Comp. Biochem. Phys. C. 149 (3), 340, 2009.

4. RYCEWICE-BORECKI M., MCLEAN J.E., DUPONT R.R. Bioaccumulation of copper, lead, and zinc in six macrophyte species grown in simulated stormwater bioretention systems. J. Environ. Manage. 166, 267, 2015.

5. PAUS K.H., MORGAN J., GULLIVER J.S., HOZALSKI R.M. Effects of bioretention media compost volume fraction on toxic metals removal, hydraulic conductivity, and phosphorous release. J. Environ. Eng. 140 (10), 1, 2014.

6. GULBAZ S., KAZEZYLLMAZ-ALHAN C.M., COPTY N.K. Evaluation of Heavy Metal Removal Capacity of Bioretention Systems. Water Air, Soil Pollut. 226 (11), 1, 2015.

7. MANGANGK I.R., LIU A., EGODAWATTA P., GOONETILLEKE A. Performance characterisation of a stormwater treatment bioretention basin. J. Environ. Manage. 150C, 173, 2015.

8. TROWSDALE S.A., SIMCOCK R. Urban stormwater treatment using bioretention. J. Hydrol. 397 (3-4), 167, 2011.
9. DAVIS A.P., SHOKOUHIAN M., SHARMA H., MINAMI C. Laboratory study of biological retention for urban stormwater management. Water Environ. Res. 73 (1), 5, 2001.

10. LU J.S., CHEN Y., ZHENG Q., RUI D.U., WANG S.P., WANG J.P. Derivation of Rainstorm Intensity Formula in Xi'an City. China water \& waste water. 26 (17), 82, 2010 [in Chinese].

11. CHEN H. The Characteristics and Simulation Study of Urban Non-point Source Pollution in Xi'an city. Xi'an: Xi'an Univ. of Tech. 2012 [in Chinese]

12. LI J.K., LI Y., ZHANG J.Y., LI H.E., LI Y.J. Bio-Swale Column Experiments and Simulation of Hydrologic Impacts on Urban Road Stormwater Runoff. Plo. J. Environ. Stud. 25 (1), 173, 2016.

13. DEBUSK K.M., WYNN T.M. Storm-Water Bioretention for Runoff Quality and Quantity Mitigation. J. Environ. Eng. 137 (9), 800, 2011.

14. ZGHEIB S., MOILLERON R., SAAD M., CHEBBO G. Partition of pollution between dissolved and particulate phases: What about emerging substances in urban stormwater catchments? Water Res. 45 (2), 913, 2011.

15. MOREIRA C.S., ALLEONI L.R.F. Adsorption of Cd, $\mathrm{Cu}, \mathrm{Ni}$ and $\mathrm{Zn}$ in tropical soils under competitive and noncompetitive systems. Sci. Agr. 67 (3), 301, 2010.

16. JONES P.S., DAVIS A.P. Spatial Accumulation and Strength of Affiliation of Heavy Metals in Bioretention Media. J. Environ. Manage. 139 (4), 479, 2013.

17. BLECKEN G.T., ZINGER Y., DELETIC A., FLETCHER T.D., VIKLANDER M. Influence of intermittent wetting and drying conditions on heavy metal removal by stormwater biofilters. Water Res. 43 (18), 4590, 2009.

18. FUERHACKER M., HAILE T.M., MONAI B., MENTLER A. Performance of a filtration system equipped with filter media for parking lot runoff treatment. Desalination, 275 (13), 118, 2011

19. GUPTA H.V., KLING H. On typical range, sensitivity, and normalization of Mean Squared Error and Nash-Sutcliffe Efficiency type metrics. Water Resour. Res. 47 (10), 125, 2011. 